\title{
O Instituto de Cultura Física de Porto Alegre/RS e suas práticas corporais (1928-1937)
}

\author{
Mônica Fagundes Dantas* \\ Carolina Dias ${ }^{* *}$ \\ Janice Zarpellon Mazo***
}

\begin{abstract}
Resumo: O estudo tem por objetivo analisar as práticas corporais oferecidas pelo Instituto de Cultura Física (ICF), a fim de compreender as representações culturais produzidas a partir dessas práticas. O ICF foi um espaço educacional fundado em 1928 na cidade de Porto Alegre, destinado ao ensino de práticas corporais femininas e perdurou até 1937, quando encerrou suas atividades. Foram privilegiados os dois primeiros anos de funcionamento do Instituto, pois nesse período consolidaram-se os princípios pedagógicos e artísticos do ICF, tributários tanto dos sistemas ginásticos quanto do método dalcrozeano. Nessa fase, o ICF produziu representações associadas aos campos dos sistemas ginásticos, da Educação Física e da Dança, tendo contribuído consideravelmente para a constituição do campo da Dança em Porto Alegre.
\end{abstract}

Palavras-chave: Educação Física e Treinamento. Ginástica Rítmica. História da Dança.

\section{INTRODUÇÃo}

O Instituto de Cultura Física (ICF) foi um espaço educacional fundado em 1928 na cidade de Porto Alegre, destinado ao ensino de práticas corporais femininas. Leonor Dreher Bercht e Philomena Black-Eckert, mais conhecidas como Nenê Berchet e Mina Black foram as idealizadoras, diretoras e professoras do Instituto. De origem

\footnotetext{
'Professora do Programa de Pós-Graduação em Artes Cênicas e do Departamento de Educaçào Física da UFRGS, Porto Alegre, RS, Brasil E-mail: modantas@yahoo.com

"Mestre em Ciência do Movimento Humano, UFRGS, Porto Alegre, RS, Brasil. E-mail: cgdias_ef@yahoo.com

"'Professora do Programa de Pós-Graduação em Ciências do Movimento Humano. Escola de Educação Física da UFRGS, Porto Alegre, RS, Brasil. E-mail: janmazo@terra.com.br
} 
alemã, constituíram trajetórias significativas no cenário artístico e esportivo de Porto Alegre, as quais possibilitaram a fundação do Instituto e a inserção das mulheres no campo das práticas corporais. Ambas descendentes de imigrantes alemães viajavam com certa frequência à Alemanha, dedicando-se ao aprendizado da ginástica e da dança. Desse modo, buscaram no modelo metodológico europeu, em especial, no método dalcrozeano e na dança expressionista, desenvolvida por Mary Wigman, subsídios teóricos e práticos para a organização estrutural do ICF, bem como para seu programa de ensino. Práticas como a Ginástica Rítmica, a Ginástica Corretiva, a Ginástica Geral, a Ginástica Acrobática, a Plástica Animada e o Estudo e a Improvisação Coreográfica constituíam a base do seu programa de ensino.

A partir desse contexto, temos por objetivo, neste artigo, analisar as práticas corporais oferecidas pelo ICF, a fim de compreender as representações culturais produzidas a partir destas práticas. Privilegiamos os dois primeiros anos de funcionamento do Instituto, pois nesse período consolidaram-se os princípios pedagógicos e artísticos do ICF, tributários tanto dos sistemas ginásticos quanto do método dalcrozeano.

O termo práticas corporais é compreendido como um conjunto de fazeres corporais, os quais se relacionam ao desenvolvimento de uma dinâmica corporal e que tem por finalidade o aprimoramento da saúde e da sensibilidade (LAZZAROTI FILHO et al, 2010). Durante o período estudado, estas manifestações encontravam-se num campo cultural mais amplo e menos institucionalizado do que o das práticas consideradas esportivas, o que as diferia do remo, do atletismo e do futebol, esportes na época. Dentre as práticas corporais que compunham o programa de ensino do ICF, destacava-se a Ginástica Rítmica, que apresentava características associadas tanto aos sistemas ginásticos quanto à dança.

Esta pesquisa se desenvolve dentro dos horizontes teóricometodológicos da História Cultural (BURKE, 2005; CHARTIER, 2000; PESAVENTO, 2008), pois este campo permite ao pesquisador interpretar representações de um tempo não vivido, construindo uma 
versão possível da realidade. Em se tratando de uma abordagem histórico-cultural, nossa concepção metodológica foi eminentemente interpretativa, visto que fomos em busca de significados construídos no passado. Investigações interpretativas fazem parte de um universo qualitativo de pesquisa e buscam compreender como os sujeitos experimentam, percebem, criam, modificam e interpretam a realidade na qual se encontram imersos. Com estes contornos, a construção deste discurso histórico se deu a partir de algumas técnicas específicas, visando à elaboração de uma versão do passado na qual se estabeleceu, constantemente, o cruzamento de duas realidades: as fontes históricas referentes ao período investigado e a interpretação dos pesquisadores.

Consideramos como fontes impressas jornais, revistas, programas de espetáculos, obras raras, almanaques, monografias, dissertações, teses e livros. Foram privilegiados os jornais portoalegrenses de maior circulação da época, como o Diário de Notícias (DN), Correio do Povo (CP) e A Federação (A FED), além do catálogo da Revista do Globo (MAZO, 2004). Tais fontes foram submetidas à técnica de análise documental (BARDIN, 2000; PINSKI, 2008). Destacamos que o Diário foi a fonte que proporcionou maior volume de informações sobre o ICF. Fundado em 1925, tornou-se o carro chefe na divulgação das artes em Porto Alegre devido à criação da sessão "Páginas Literárias" e à migração, em 1927, de muitos autores do jornal Correio do Povo para seu corpo editorial (FERNANDES, 2009).

As principais fontes imagéticas utilizadas na construção dos dados foram aquelas que reportavam às práticas ministradas no $\mathrm{ICF}$, presentes nas fontes impressas e/ou nos programas de espetáculos. A interpretação das imagens foi realizada com base na proposta metodológica de Kossoy (1999).

O estudo busca contribuir para o campo da História da Educação Física e do Esporte, mas, especialmente para o campo da História da Dança. Geralmente, os estudos em história da dança privilegiam, ainda, as biografias de personalidades relevantes (MEIRELLES; MANTELLI, 1989, FREIRE, 2002). Há uma carência de pesquisas 
historiográficas sobre instituições que fomentaram práticas corporais relacionadas à dança, como ICF, o qual se consagrou como um lugar privilegiado na formação de precursoras da dança cênica.

\section{A GINÁSTICA RíTMICA: UMA ORIENTAÇÃO PARA O ICF}

Dentre as práticas que eram desenvolvidas no ICF estavam a Ginástica Corretiva, a Ginástica Rítmica, a Plástica Animada, a Ginástica Geral e os Estudos e Improvisações Coreográficas.

A partir das reportagens publicadas pelo Diário de Noticiais, acreditamos que a o foco do ICF era o desenvolvimento da Ginástica Rítmica. Desse modo, a Ginástica Rítmica era a principal referência no programa educativo do Instituto. A descoberta de que em tudo havia ritmo - nos movimentos, na respiração, na circulação do sangue, nas próprias emoções e nos pensamentos - e que estes davam expressão à vida, reforçava a preferência por uma prática que incluísse um sentido musical. Desse modo, a Ginástica Rítmica surge como um novo método de educação que era diferente das outras ginásticas por ser considerada, ao mesmo tempo, como ciência e como arte. Surgia, igualmente, pela necessidade dos indivíduos de encontrarem um equilíbrio entre as faculdades intelectuais, emotivas e físicas, visto que no dado momento histórico era exigido o balanço perfeito entre estes três pilares (DO VALOR..., 1929). E, além disso, era advinda da Europa.

A Revista do Globo (ARTES..., 1931) aponta como os fundadores desta ginástica moderna, Isadora Duncan e JaquesDalcroze. Duncan (1877-1927) apresentou ao mundo uma dança composta por gestos rítmicos inspirados na cultura grega. Sua técnica e método seriam inspirados por uma corrente neo-helenica, onde os princípios naturais predominariam. Não obstante a clara referência à Duncan feita pela Revista do Globo, podemos, atualmente, indagar se ela pode ser considerada como uma das fundadoras da Ginástica Rítmica, ou se seria mais evidente pensá-la como uma de suas inspiradoras, pois, de acordo com autores como Norman (1993) e com escritos da própria artista (DUNCAN, 1989; 1996), sua atuação 
visava, principalmente, desenvolver um projeto artístico e um sistema próprios de ensino da dança. Podemos especular que, talvez, na época, não houvesse tanta distinção entre a Ginástica Rítmica e formas de dança que não fossem o ballet ou as danças folclóricas e que, desse modo, a dança de Duncan poderia ser associada à Ginástica Rítmica.

Já as idéias de Émile Jaques-Dalcroze (1869-1950) começam a ser difundidas a partir de 1910, com a abertura de seu instituto em Hellerau, na Alemanha. Seu método se propunha a reavivar o sentimento rítmico através da realização de movimentos em acordo com compassos e intervalos musicais. Para Dalcroze, a educação corporal deveria ocorrer através da música, destacando a complementaridade existente entre o desenvolvimento motor e as capacidades mais sensíveis do ser humano. Assim, considerava que Ginástica seria a base para a educação do corpo e da saúde. Já a ginástica rítmica traria ao corpo, higienicamente desenvolvido pela ginástica elementar, "[...] o espírito da graça e uma série de exercícios cujo fim é educar os centros nervosos" (MEYER, 1944, p. 11).

O programa dalcrozeano se sustentava em três pilares: harmonia e solfejo, euritimia, improvisação (MEAD, 1996). Estas práticas foram adaptadas à perspectiva de ensino do ICF. Estavam presentes, mesmo que com outras denominações, nas aulas ministradas por suas instrutoras.

Os exercícios desenvolvidos no ICF, todos permeados pelo viés dalcrozeano, tinham por intuito desenvolver o sentido musical através de movimentos relativamente simples, como bater palmas, caminhar, mover os braços, cantar e tocar um instrumento. Tais atividades tornavam-se mais complexas pela alternância entre ritmos lentos e rápidos e objetivavam o aprimoramento do sentido auditivo, visando a internalização do tempo musical. Estas movimentações mais naturais (MEAD, 1996) também incluíam o desafio de reconhecer e aprimorar certa noção de espacialidade.

No entanto, este era somente um, entre outros aspectos, do desenvolvimento do sentido musical. Para além da aquisição do ritmo, o Diário de Notícias afirmava que a Ginástica Rítmica era um 
importante fator para o desenvolvimento das faculdades artísticas como a imaginação, o sentido de equilíbrio, a consciência de proporções e de harmonia, de formas, linhas e volumes (DO VALOR..., 1929). Desse modo, a Ginástica Rítmica era também considerada arte, sendo comparada às artes plásticas e à música, pois propiciava o aprimoramento intelectual e emotivo, bem como o apuro dos sentidos (GINÁSTICA..., 2004).

Para Meyer (1944), a Ginástica Rítmica seria a congregação entre a ginástica e a música. $\mathrm{O}$ desenvolvimento do corpo como um todo era um dos ideais desta prática, que propiciava o aprimoramento das capacidades mentais e espirituais do indivíduo. A ideologia da Ginástica Rítmica era permeada pela crença na necessidade de desenvolver o corpo e a mente em harmonia. Meyer $(1944$, p.8) aponta que "[...] não foi pelo corpo nem pela inteligência que o homem se tornou um ser superior e sim pela união vivificadora que a matéria contraiu com o espírito e a alma". A Ginástica Rítmica não possuía, nesse sentido, a pretensão de ser chamada de arte da dança, pretendia, sim, educar o corpo através do ritmo e adquirir o status de proporcionar o desenvolvimento integral. Meyer (1944) ressalta que a ginástica seria o treinamento do corpo sem aparelhos; já o ritmo se associaria ao aspecto subjetivo, seria a própria expressão do corpo enquanto manifestação da alma. Nesse sentido, o ritmo conduziria os gestos e estaria presente na vibração dos movimentos e a aliança entre movimento e ritmo permitiria uma comunicação corporal mais completa.

Entretanto, mesmo que a Ginástica Rítmica não se apresentasse como arte, não havia limites claros entre esta proposta de ginástica e o que seria considerado como dança. Em determinados momentos, a Ginástica Rítmica e a Dança apareciam como complementares. Em outros, eram tratadas quase como sinônimos, pois os movimentos desenvolvidos pela Ginástica Rítmica sugeriam, cada vez mais, representações ligadas aos movimentos dançados. Assim, divulgavam-se opiniões como: 
[...] a verdadeira dança, como a praticavam os gregos e como Krisshna a ensinava, na India as amorosas gopis, é a arte dos rythmos applicada aos movimentos do corpo humano. A verdadeira dança, a dança nobre, creadora de attitudes plásticas, é o coroamento da gymnastica, porque, assim como os exercícios de gymnastica culminam no domínio do espírito sobre o corpo, os gestos gymnasticos culminam na harmonia dos movimentos plásticos que, succedendo-se uns aos outros, cream esse rythmo maravilhoso que se chama dança (OS EXERCÍCIOS..., 1929).

Vemos indícios de como o campo da dança, nesse período, estava se constituindo na cidade de Porto Alegre. Danças como o charleston, o black-botton, e o fox-blue eram denominadas danças modernas. Eram praticadas nos salões e consideradas, pelos integrantes e simpatizantes do movimento higienista e eugenista, como hábitos inúteis e conseqüência do mau gosto e da falta da cultura física incorporada (OS EXERCÍCIOS..., 1929). Por outro lado, a "verdadeira dança", conforme anunciado na citação anterior, não era algo à parte da cultura física almejada e não estava apartada da ginástica, mas representava a culminância dos movimentos ginásticos. $\mathrm{O}$ autor percebe que a fluidez dos movimentos é um dos elementos que transforma o movimento ginástico em gesto dançado, permitindo a criação de um ritmo próprio, talvez diferente do ritmo sustentado e regular dos exercícios ginásticos. Do mesmo modo, quando observadas as imagens das alunas do Instituto realizando seus exercícios diários, ressaltam-se muitos aspectos similares àqueles das práticas que consideraríamos hoje como dança.

De fato, movimentações encadeadas que remetiam à idéia de uma coreografia estavam presentes nos espetáculos do ICF. E poderiam ser consideradas danças, mas ainda não legitimadas como tal. Assim, as demonstrações públicas promovidas pelo ICF pareciam produzir diferentes representações: ora associadas ao campo da dança, numa concepção que apartava as danças dos salões da "verdadeira dança", ora ligadas ao campo da ginástica. 


\section{A plástica ANimada}

Cunha e Franck (2004) fazem a ressalva de que, para além da Ginástica Rítmica, a Plástica Animada era mais uma das classes desenvolvidas pelo ICF. De fato, os denominados Movimentos Plásticos eram realizados logo após os elementos da Ginástica Rítmica, sendo associados aos Estudos de Expressão. Explicita-se que se identificava como Movimentos Plásticos a realização de poses que remetessem a estátuas gregas. Já nos Estudos de Expressão, as alunas buscavam representar emoções como dor e alegria, bem como realizar exercícios que imitassem elementos naturais como o mar, as nuvens, o vento. (COMO CONDUZIR..., 1929).

Na perspectiva de Dalcroze, a Plástica Animada figurava como um dos ramos de ensino que compunham o grande grupo da Ginástica Rítmica. Cabe ressaltar que a concepção de Plástica Animada de Dalcroze foi influenciada pela obra de François Delsarte (1811-1871). Delsarte dedicava-se às artes em geral, elaborando teorias para as artes plásticas, a música, o canto e o teatro. Para ele, a intensidade do sentimento comandaria o gesto, ao contrario de Dalcroze, que acreditava que o gesto e os sentimentos seriam guiados, exclusivamente, pela música.

Na perspectiva do método dalcrozeano, a Plástica Animada centrava-se nas possibilidades rítmicas da música, explorando as variações da dinâmica musical e o seu tempo de duração, mas também possibilitava "[...] criar formas decorativas e expressivas de movimento sem o apoio do som, com o suporte exclusivo da música interior" (DALCROZE. apud SOUZA, 2011, p. 192). Segundo Guérios (1957), as Marchas Rítmicas, compostas por movimentos como correr, saltar e saltitar, compunham parte de uma sessão de Plástica Animada; caracterizavam-se como exercícios que exigiam elasticidade, agilidade e flexibilidade das pernas realizado nos "tempos animados" (GUÉRIOS, 1957, p. 21).

A Plástica Animada partia de um gesto, buscando a fluidez na transição de uma atitude para a outra. O objetivo seria o encadeamento dos movimentos que constituíam essa transição, 
formando a frase do movimento (GUÉRIOS, 1957). Dalcroze associava a Plástica Animada a um extremo aperfeiçoamento musical. Acreditava que a Plástica e a Música eram duas artes que, por serem da mesma natureza, complementavam-se. Mesmo reconhecendo a expressividade dos Movimentos Plásticos, Dalcroze postulava que a expressão e a emoção do corpo emergiam da música. No entanto, considerava que a música era algo intrínseco ao ser humano. Por isso, como explica Souza (2011, p. 192), Dalcroze admitia que "[...] a experimentação de movimentos livre de estruturas musicais deveria ser considerada e explorada em seu método" (), uma vez que a musicalidade e o sentido ritmo já haviam sido internalizados.

A despeito das práticas e crenças desenvolvidas no ICF, acreditamos que Plástica Animada, além de visar a representação de estátuas gregas, desenvolvendo a expressão corporal a partir de certas representações da cultura helênica, buscava justamente promover a fluidez entre movimentos. Este termo aproximava, igualmente, as atividades do ICF do campo das artes, mais especificamente da dança e das artes plásticas, pois indicava a existência de elementos plásticos como linhas e formas nas práticas corporais cultivadas no ICF (AS QUALIDADES..., 1929).

\section{A ginÁstica CoRretiva e ACROBÁtICA}

Se a Ginástica Rítmica era a principal referência no ICF, as outras práticas ginásticas eram tratadas como complementares. Elas traziam resquícios de um método já considerado antigo, a Ginástica Sueca, representada através da Ginástica Geral e Corretiva. Entretanto, tais práticas ainda eram consideradas a base para o desenvolvimento corporal das alunas, pois visavam a correção postural.

Como exemplo destes indícios, temos trechos do Diário de Notícias: 
evolução incalculável sobre a gymnastica antiga, comummente chamada de sueca, embora existam diversos methodos. [...] A differença entre a gymnastica rythmica e a sueca é tão grande como, por exemplo, é a existente entre as matérias de um curso primario e as de uma universidade. É um absurdo querer fazer uma comparação de valores entre uma e outras, como seria absurdo tentar estabelecer um confronto entre um curso primário e um curso universitário, pois este segundo tem que incluir forçosamente o primeiro, como a gymnastica rythmica inclue a gymnastica correctiva, respiratória e acrobática, etc. e a sua acção não se limita ao desenvolvimento muscular, mas se afunda, por assim dizer até o ser psychico e actua sobre os sentimentos como sobre o intellecto (DO VALOR..., 1929).

Na perspectiva da reportagem do jornal Diário de Notícias, a Ginástica Corretiva era um elemento que contribuía para o desenvolvimento corporal, mas não seria suficiente para o desenvolvimento integral do corpo, principalmente para o corpo feminino. No ICF, normalmente, as alunas iniciavam pela aula de Ginástica Corretiva. Para Marinho ([1970?], p. 55) esta modalidade "[...] tem por finalidade o restabelecimento do equilíbrio do antagonismo muscular e utiliza exercícios específicos, que visem a encurtar os músculos que estão alongados ou alongar os que estão encurtados". Esta descrição nos leva a crer que a Ginástica Corretiva visava desenvolver a flexibilidade, bem como tonificar os músculos por meio de exercícios isométricos.

Outros indícios das finalidades da Ginástica Corretiva, também são encontrados em imagens divulgadas pela Revista do Globo, as quais apresentavam imagens de diferentes exercícios de alongamento, sugerindo sua realização às mulheres que queriam manter a forma e a saúde. Nos exercícios de Ginástica Corretiva, havia igualmente a preocupação com o desenvolvimento da respiração, por considerar que esta era fonte de energia e de vitalidade (A AUTORIZADA..., 1929). 
Embora a Ginástica Acrobática não estivesse inserida no currículo do ICF, era anunciada nos programas dos espetáculos, seguindo ou substituindo a Ginástica Corretiva. Isso nos leva a crer que as qualidades físicas cultivadas pela Ginástica Acrobática eram, igualmente, trabalhadas nas aulas de Ginástica Corretiva. Dentre as qualidades físicas mais importantes a serem desenvolvidas pela Ginástica Acrobática estava a flexibilidade (SERATA..., 1935). Para as mulheres, indicava-se trabalhar a flexibilidade tanto dos membros inferiores, em virtude não só do desenvolvimento da graça e da linha dos movimentos, mas beneficiando a futura maternidade (GOELLNER, 1999). Do mesmo modo, estimulava-se a "dilatação do peito" a fim de melhorar o porte e a respiração no corpo feminino.

Para além da aquisição de flexibilidade, elementos como o equilíbrio e os saltos pareciam ser trabalhados nas classes de Ginástica Acrobática. Segunda a Revista do Globo (EDUCAÇÃO..., 1938) na cultura grega, as mulheres executavam danças acrobáticas nas quais elevavam os pés acima das linhas das estatuetas. No entanto, as proezas acrobáticas não eram tão recomendadas às mulheres. Nesse sentido, aconselhava-se àquelas que desejavam modelar suas formas, tornando-se mais femininas, a preferência pelas atividades rítmicas:

Em se tratando da belleza da mulher moderna, devese frizar, desde logo, que é de uma importância capital para o aperfeiçoamento das linhas estheticas e especialmente para maior graça e elegancia, fazer uso dos exercícios rythmicos, de conformidade com os preceitos modernos. Nem somente do desporto, que falha nas suas finalidades pelo embrutecimento das formas e dos movimentos. [...] entretanto se reunimos o desporto ao exercício rythmico, terse-á o que de mais bello se pode imaginar. Não se pode desmentir ou deixar passar desapercebido o perigo que existe no modo por que é praticado o desporto atualmente. [...] é precizo combatelo, pelo exercício rythmico, para se conseguir a graça e a belleza. $\mathrm{O}$ exercício rythmico é justamente a arte de fazer com que a mulher tome posições elegantes e firmes (PATEK, 1929). 
O artigo publicado no Diário de Notícias (UMA OBRA..., 1929), foi escrito por Claire Patek na revista alemã Sonnige Wlet, a qual publicava informações acerca da cultura física feminina. As ideias de Claire eram semelhantes às veiculadas pelo Diário de Notícias sobre o método ginástico.

\section{O ESTUdO E A IMPROVISAÇÃO COREOGRÁFICA: A EMERGÊNCIA DA DANÇA}

Desde o primeiro ano de sua fundação, o ICF realizava espetáculos em espaços consagrados pela elite porto-alegrense, como o Teatro São Pedro, tendo realizado, no período estudado, ao menos um espetáculo por ano. Normalmente, a ordem de apresentação das atrações seguia a lógica do programa de ensino proposto. Assim, os espetáculos iniciavam pelas demonstrações de Ginástica Corretiva e Acrobática. Após, vinham a Ginástica Rítmica e os Movimentos Plásticos, geralmente, associados à representações da cultura helênica. E, para o último momento, guardava-se a apresentação das coreografias inspiradas em culturas do oriente ou em elementos da natureza.

O resultado final da reunião das modalidades concretizava-se nas grandes cenas organizadas pelo ICF, que materializavam os propósitos da Ginástica Rítmica: um conjunto de práticas que desenvolvia o sentido rítmico através do corpo e que, ao final, se transformava em algo similar a composições coreográficas. Desse modo, a difusão da Ginástica Rítmica incrementou a propagação de um novo caráter de composição dos movimentos, participando do processo de delimitação do campo da dança em Porto Alegre. A partir de então, esta dança veiculada no ICF começa a ser identificada como dança acadêmica.

Segundo o Diário de Notícias (12/12/1929, p. 5) a arte acadêmica seria considerada tradicional pela conservação das regras e convenções artísticas, tais como o espaço em perspectiva; o desenho com primazia sobre a cor; a busca de uma beleza ideal, que revelasse o "bom gosto"; o equilíbrio entre os planos e a harmonia na 
composição. Nessa direção, estavam as coreografias temáticas criadas pelo ICF e que, nos programas dos espetáculos, constavam como último item de apreciação do público. Entretanto, se a dança que emergia no ICF buscava maior rigor nas composições, visando harmonia e bom gosto, ainda não conseguia se estabelecer como uma dança clássica, de tradição acadêmica, nos moldes do ballet europeu.

Nesse sentido, as aulas de Estudos Coreográficos e de Improvisação Própria de Coreografia, que integravam a fase final do programa curricular do ICF, deveriam contribuir para a constituição dessa dança. As duas práticas pareciam congregar a gama de habilidades desenvolvidas através dos exercícios preliminares de ginástica, contemplando as aptidões adquiridas através da Ginástica Rítmica, conduzindo-as para a organização de movimentos coreografados.

As aulas de Estudos Coreográficos visavam a construção de blocos coreográficos a partir da escolha de diferentes temas, nos quais eram desenvolvidas habilidades de memorização, exploração dos movimentos do corpo e interpretação cênica. Estes itens podem ser identificados nos programas dos espetáculos, no quais sempre havia um momento destinado à apresentação de diferentes coreografias. No espetáculo "A Lenda da Princesa Moura" (1930), por exemplo, constam diversas danças típicas, que se inspiravam no imaginário de culturas exóticas, principalmente orientais (A PRINCEZA..., 1930). Essas danças apresentavam uma complexidade crescente de estruturação espacial e rítmica, quando comparadas às demonstrações ginásticas.

Os Estudos de Improvisações Coreográficas destinavam-se a alunas que já possuíam repertório corporal. Buscavam desenvolver a espontaneidade por meio da criação de movimentos. Tal abordagem provavelmente se baseava nos ensinamentos de Mary Wigman (18861973) que, participando do Movimento Expressionista, via nos exercícios de improvisação um meio de compor suas coreografias (FAHLBUSCH, 1990). Para Wigman, a formação em dança não deveria começar por uma disciplina que levasse a moldar os gestos 
segundo modelos estabelecidos, mas sim por tentativas, de início instintivas, através das quais seria possível torna-se consciente do que ser quer exprimir. Num segundo momento, buscar-se-ia a cristalização artística dos impulsos primeiros (GARAUDY, 1980). Essas práticas estavam de acordo com a concepção de que o corpo da mulher deveria ser trabalhado para se expressar de forma "natural", propiciando o desenvolvimento de campos mais subjetivos, favorecendo a criatividade e o desembaraço das mulheres em sociedade (SCHPUN, 1999).

Paralelo à presença dos princípios de Wigman, são também identificadas representações ligadas ao imaginário duncaniano. As idéias de Isadora Duncan inspiraram o ensino da dança na Europa e, em particular na Alemanha, onde estudaram as fundadoras do ICF. Nesse quadrante, circulava na imprensa porto-alegrense a divulgação de duas correntes de dança que viriam a mudar a perspectiva do ICF: primeiro, a presença dos paradigmas expressionistas e duncanianos, que, ao final de 1930, começam a ser veiculados enquanto um novo estilo de arte. De acordo com a imprensa, a expressão estética do expressionismo alemão possuía um sabor revolucionário, quando comparada ao romantismo representado pela bailarina clássica Marie Taglioni ${ }^{1}$ ou aos rigores da Escola Imperial de Bailados da Rússia (CHINITA..., 1931).

Uma segunda corrente de pensamento estava associada aos "bailados russos" de Serge Dialghiev, conhecidos por antecipar "[...] o gosto do exigente público parisiense" (LEVONIAN, 2004, p. 205). Reunindo em seus espetáculos artistas de vanguarda como o compositor Igor Stravinski, pintores como Leon Bakst e Pablo Picasso e coreógrafos como Michel Fokine e Vaslav Nijinski, as produções de Diaghilev partiam de uma matriz técnica oriunda do ballet romântico, mas eram inovadoras. Em Porto Alegre, como na Europa, eram identificadas como grandes feitos artísticos, pois os espetáculos apresentados eram dotados de elementos plásticos e estéticos de grande valor:

${ }^{1}$ Pertencente a aristocracia, a família Taglioni foi responsável pelo desenvolvimento e legitimação do estilo romântico no ballet, sendo uma das primeiras a dançar em pontas (LEVONIAN, 2004). 
Os espetáculos choreographicos, depois da grande obra renovadora que pela ressurreição da arte dos bellos gestos e da plástica animada realizou Isadora Duncan, se tornaram cada vez mais os preferidos, entre todos os outros, nos grandes meios cultos. É o que explica o extraordinário êxito que tem alcançado as numerosas escolas de gymnastica rytmica e de dança artística, esparsas nas capitaes européas e principalmente na Allemanha, o sucesso da "troupe" de bailados russos de Sergio Diaghllew e o florescimento, sempre crescente da nobre arte de que em nosso tempo, a incomparável Isadora Duncan foi o gênio animador e Jacques Dalcrose um dos seus maiores propulsores. Em Porto Alegre o Instituto de Cultura Physica tem trazido para o nosso meio o interesse pelos espetáculos choreographicos, realizando aqui, com a nossa mocidade feminina, o que Jacques Dalcrose realisa, na Europa, com os institutos numerosos que adoptam o seu methodo de desenvolvimento plástico feminino, o que Isadora Duncan sonhava ao fundar, na Grécia e depois em outros paizes, a sua escola de danças clássicas (A PRINCEZA..., 1930).

Iniciadas pela imprensa a partir de 1930, as divulgações acerca da dança clássica destacavam e, deveras, solicitavam, ainda que de forma não anunciada, a inserção de um novo fazer corporal, considerado mais acadêmico. O ICF, através de seus espetáculos anuais, além de despertar o gosto da sociedade por um novo sentido estético do corpo em movimento, estava prestes a participar da inserção dos primeiros rastros do que elencamos como ballet. Tal prática passaria ser divulgada por uma de suas alunas e futura professora, Lya Bastian Meyer, através das aulas de Dança Clássica.

No espetáculo "A Lenda da Princesa Moura" já surgiam os estímulos pela aceitação de uma nova prática ligada ao imaginário da Dança Clássica. Em uma das coreografias intitulada "Jardim Encantado", as moças executavam uma das primeiras coreografias com "ares" de ballet, nas pontas dos pés (REVISTA DO GLOBO, [1930?], citado por MAZO, 2004). Segundo Morgada Cunha, ao

Movimento, Porto Alegre, v. 19, n. 01, p. 33-53, jan/mar de 2013. 
invés do arcabouço de gesso utilizado nas pontas para a sustentação das bailarinas, as alunas do ICF colocavam algodão na parte anterior das sapatilhas para conseguirem subir sobre os dedos. Suas intenções eram representar ideais de leveza e graça.

Desde então, o ICF começa a construir representações que anunciavam mudanças tanto no programa de ensino quanto na inserção de uma nova prática na sociedade porto-alegrense. Nesse sentido, tem início um período que caracterizaria uma nova fase para o ICF, atrelado à inserção da dança clássica. Em 1937, o ICF passa a se chamar Escola de Bailados Tony Seitz Petzhold.

\section{Considerações finAs}

Durante sua trajetória, o ICF passou basicamente por duas fases demarcadas pelas fronteiras que constrói com as práticas corporais que incorpora no seu programa de ensino. A primeira fase analisada no presente artigo abarca o período da fundação datada do ano de 1928 até 1930, e a segunda é delimitada de 1931 até 1937. A primeira produziu representações associadas ao campo dos sistemas ginásticos e aos discursos que, igualmente, associavam-se ao campo da Educação Física. Esse fato se sustenta no indício de que o ICF propunha-se a desenvolver a cultura física, através da Ginástica Feminina Moderna, identificada também como Ginástica Rítmica. Já a segunda fase do ICF caracteriza-se pela ruptura gradual com o sistema ginástico adotado nos primeiros anos de funcionamento. A partir de 1931 começam a serem privilegiadas práticas corporais relacionadas à dança, principalmente a chamada dança clássica.

A Ginástica Rítmica era a principal prática difundida pelo ICF e estava inclusa nas novas demandas normatizadoras da sociedade. Tratavam-se, de fato, de práticas corporais sistematizadas e particulares, utilizadas como uma forma de inculcar um determinado modo de ser e agir nos atores sociais envolvidos. Ainda, a primeira fase do Instituto foi o momento em que tal instituição encontrou maior repercussão na cidade de Porto Alegre, pelas inovações que estavam sendo instauradas e pela ressonância com os projetos de 
edificação e fortalecimento da nação. Paralelamente, este período caracterizou-o como uma filial do Instituto de Ritmo Aplicado Jacques Dalcroze, conferindo o patamar social de ser uma instituição eminentemente europeia.

Entretanto, é ainda nesse período que as práticas do ICF produzem representações associadas também ao campo da dança. Inferimos que a acentuação do caráter coreográfico dos espetáculos apresentados pelo ICF, ancorados na Ginástica Rítmica, na Plástica Animada e nos Estudos e Improvisações Coreográficas foi um fator que contribuiu consideravelmente para a constituição desse campo em Porto Alegre. Essas práticas foram o resultado de um processo de formulação de novos conceitos no campo da ginástica e das artes, alavancados no cerne do teatro, da música e da dança.

As idéias advindas dos "inspiradores" - François Delsarte, Émile Jaques-Dalcroze, Isadora Duncan, Mary Wigman - que influenciaram a construção da Ginástica Rítmica, bem como da dança expressionista, foram importadas e (re)significadas. Em Porto Alegre, contribuíram para a fundação de espaços destinados a desenvolver tais concepções, como o ICF. Entretanto, os movimentos, por ocorrerem em ambientes culturais por vezes diferentes e, também, por serem iniciados por pessoas com hábitos e trajetórias distintas, organizaram-se de modos, obviamente, desiguais. Estas cadeias de acontecimentos, que se influenciam entre si, demonstram a possibilidade de em um só espaço, conter a presença de ideias de diferentes lugares, demonstrando o constante processo de transformação dos fenômenos. Nesse sentido, os espetáculos apresentados pelo ICF foram emblemáticos. Embora influenciadas por movimentos artísticos considerados renovadores da dança e que, de certa forma, desestabilizavam os cânones da dança acadêmica, identificada ao ballet, apresentavam claras referências a essa prática, como o uso de sapatilhas de pontas. Tal fato ocorreu já num de seus primeiros espetáculos, "A Lenda da Princesa Moura". 
Physical Culture Institute and its body practices Abstract: The study aims to examine body practices offered by the Physical Culture Institute (PCI), in order to understand cultural representations produced from these practices. PCI was an educational space founded in 1928 in Porto Alegre city, for the teaching of female bodily practices. The first two years of operation of the Institute were privileged, for the pedagogical and artistic principles of the $\mathrm{PCl}$ were consolidated in this period, both tributaries of gymnastic systems and dalcroziano method. In this phase, $\mathrm{PCI}$ produced representations associated to the gymnastic systems, Physical Education and dance fields, and has greatly contributed to the establishment of the dance field in Porto Alegre.

Key words: Physical Education and Training. Rhythmic Gymnastics. Dance. History

\section{EI Instituto de Cultura Física y sus prácticas corporales}

Résumen: El estudio tiene por objeto analizar las prácticas corporales que fueron ofrecidas por el Instituto de Cultura Física (ICF), con el intuito de comprender las representaciones culturales producidas a partir de estas prácticas. El ICF fue un espacio educacional fundado en 1928 en la ciudad de Porto Alegre, destinado a la enseñanza de prácticas corporales femeninas. Los dos primeros años de funcionamiento de este Instituto fueron privilegiados, pues, en ese periodo, los principios pedagógicos y artísticos del ICF fueron consolidados, tributarios tanto de los sistemas gimnásticos como del método dalcroziano. En esta fase, ICF ha producido representaciones asociadas a los campos de los sistemas gimnásticos, de la Educación Física y de la danza, contribuyendo en gran medida para la constitución del campo de la danza en Porto Alegre.

Palabras-clave: Educación y Entrenamiento Físico. Gimnástica Rítmica. Historia de la Danza 


\section{REFERÊNCIAS}

A AUTORIZADA opinião do dr. Mario Totta sobre o valor da cultura física. Diário de Notícias, Porto Alegre, 20 out. 1929. Não paginado.

ARTES, cultura physyca feminina. Revista do Globo, Porto Alegre, v. 3, n. 49, p. 11, 10 jan. 1931.

BARDIN, L. Análise de conteúdo. Lisboa: Edições 70, 2000.

BURKE, P. O que é história cultural. Rio de Janeiro: Zahar, 2005.

DIÁRIO de Notícias. Porto Alegre, 12 dez. 1929. Não paginado.

COMO CONDUZIR a mulher moderna à busca da belleza. Diário de Notícias, Porto Alegre, 18 ago. 1929. Não paginado.

CHARTIER, R. A história cultural: entre práticas e representações. Lisboa: DIFEL, 2000.

CHINITA Ullmaann e Carleto Thieben. Diário de Notícias, Porto Alegre, 12 ago. 1931. Não paginado.

CUNHA, M.; FRANK, C. F. Dança: nossos artífices. Porto Alegre: Movimento, 2004.

DIAS, C. Histórias do Instituto de Cultura Física de Porto Alegre (19281937). 2011. Dissertação (Mestrado em Ciências do Movimento Humano). - Escola de Educação Física, Universidade Federal do Rio Grande do Sul, Porto Alegre, 2011.

DO VALOR da cultura physica para a educação de menores anormaes. Diário de Notícias, Porto Alegre, 27 out. 1929. Não paginado.

DUNCAN, I. Minha vida. Rio de Janeiro: José Olympio, 1989.

Fragmentos autobiográficos. Porto Alegre: L\&PM, 1996.

EDUCAÇÃO física: a dansa até os nossos dias de hoje. Revista do Globo, Porto Alegre, 14 set. 1938. Nãompaginado.

OS EXERCICIOS de gymnastica para a graça do corpo em movimento. Diário de Notícias, Porto Alegre, 21 jul. 1929. Não paginado.

FAHLBUSCH, H. Dança moderna e contemporânea. Rio de Janeiro: Sprint, 1990. 
FERNANDES, D. Representações da Semana de Arte Moderna e dos modernistas na imprensa de Porto Alegre (1922-1928). Monografia (Graduação em História) - Universidade Federal do Rio Grande do Sul, Porto Alegre, 2009.

FREIRE, A. L. G. Tony Petzhold: uma vida pela dança. Porto Alegre: Movimento, 2002.

GARAUDY, R. Dançar a vida. Rio de Janeiro: Nova Fronteira, 1980.

GINÁSTICA ritmica. In: MAZO, J. Esporte e educação Física na Revista do Globo: catálogo. Porto Alegre: FEFID/PUCRS, 2004. CD ROM.

GOELLNER, S. Bela, maternal e feminina: imagens da mulher na Revista Educação Physica. Tese (Doutorado em Educação) - Universidade de Campinas, Campinas, 1999.

GUÉRIOS, S. F. M. Ginástica rítmica e a plástica animada de Dalcroze. São Paulo, 1957.

KOSSOY, B. Realidades e ficções na trama fotográfica. Cotia, SP: Ateliê, 1999.

LAZZAROTI FILHO, A. et al. O termo práticas corporais na literatura científica brasileira e sua repercussão no campo da Educação Física. Movimento, Porto alegre, v. 16, n. 1, p. 11-29, 2010.

LEVONIAN, R. História da Dança e das artes auxiliares I. Canoas: ULBRA, 2004.

MARINHO, I. Sistemas e métodos de Educação Física. São Paulo: O Autor, [1970?].

MAZO, J. Esporte e educação Física na Revista do Globo: catálogo. Porto Alegre: FEFID/PUCRS, 2004 CD ROM.

MEAD, V. More than movement. Music Educators Journal, v. 82, p. 38, 1996.

MEIRELLES, R.; MANTELLI, G. Trajetória de uma sapatilha: 50 anos de dança de João Luiz Rolla. Porto Alegre: RGM Artes, 1989.

MEYER, D. Gênero e educação: teoria e política. In: LOURO, G.; NECKEL, J. F.; MEYER, L. Ginástica Ritmica: a moderna Educação Física e Psíquica para a criança e a Mulher. Porto Alegre: Oficinas Gráficas da Tipografia do Centro, 1944.

NORMAN, S. Le corps qui se conte: quelques recherches d'une ontologie corporelle au 20ème siècle. In BRUNI, C. (Org.). Danse et pensée: une autre scène pour la danse. Paris: Germs, 1993, p. 193-202.

PATEK, Claire. A belleza da mulher moderna. Diário de Notícias, Porto Alegre, 11 ago. 1929. Não paginado. 
PESAVENTO, S. J. História e história cultural. Belo Horizonte: Autentica, 2008.

PINSKI, C. B. Fontes históricas. São Paulo: Contexto, 2008.

A PRINCEZA moura. Revista do Globo, Porto Alegre, 1930. Não paginado.

AS QUALIDADES e os defeitos physicos da mulher moderna. Diário de Notícias, Porto Alegre, 07 jul. 1929. Não paginado.

SCHPUN, M. Beleza em jogo: cultura física e comportamento em São Paulo nos anos 20. São Paulo: Boi Tempo, 1999.

SERATA de ritmica e ballet. Correio do Povo, Porto Alegre, 1935. Não paginado.

SOUZA, E. T. O sistema de François Delsarte: o método de Émile JaquesDalcroze e suas relações com as origens da dança moderna. Dissertação (Mestrado em Artes) - Universidade de Brasília, Brasília, 2011.

UMA OBRA grandiosa a realizar-se no Rio Grande do Sul. Diário de Notícias, Porto Alegre, 11 ago. 1929. Não paginado.

Endereço para correspondência:

Mônica Fagundes Dantas

Rua Surupá, 76/404

Jd Botânico

CEP- 90 690-290

Recebido em: 18.10.2012

Aprovado em: 05.11.2012

Movimento, Porto Alegre, v. 19, n. 01, p. 33-53, jan/mar de 2013. 